\title{
Comportamento ingestivo e metabólico de bovinos alimentados com ração contendo probióticos
}

\section{Ingestive and metabolic behavior of bovines fed rations containing probiotics $^{1}$}

\author{
Fernando Luiz Massaro Junior ${ }^{2}$; Leandro das Dores Ferreira da Silva ${ }^{3 *}$; \\ Ana Paula de Souza Fortaleza ${ }^{3}$; Fernando Henrique Brussi Beran ${ }^{4}$; \\ Valdecir de Souza Castro ${ }^{5}$; Edson Luis de Azambuja Ribeiro ${ }^{3}$; \\ Marco Aurélio Alves de Freitas Barbosa ${ }^{3}$; Valter Harry Bumbieris Junior ${ }^{3}$; \\ Ivone Yurika Mizubuti³; Odimári Pricila Pires do Prado ${ }^{3}$
}

\section{Resumo}

O objetivo deste trabalho foi o de avaliar a inclusão de cultura de Saccharomices cerevisiae e Lactobacillus casei na dieta de bovinos, sobre o consumo e digestibilidade da matéria seca (MS), matéria orgânica $(\mathrm{MO})$, proteína bruta $(\mathrm{PB})$, fibra em detergente neutro (FDN) e da fibra em detergente ácido (FDA), $\mathrm{pH}$ e nitrogênio amoniacal $\left(\mathrm{N}-\mathrm{NH}_{3}\right)$ no líquido ruminal e nitrogênio ureico plasmático (NUP). As rações foram isoprotéicas $(13,04 \% \mathrm{~PB})$ e isoenergéticas $(66,39 \% \mathrm{NDT})$, sendo a silagem de sorgo usada como volumoso $\left(50 \%\right.$ da MS). Foram utilizados seis machos castrados, mestiços ( $1 \frac{1}{2}$ Holandêsx $1 / 2$ Gir $)$, com peso médio de $317 \mathrm{~kg}$ e 24 meses de idade, dotados de cânula permanente no rúmen. Os tratamentos foram determinados como controle (sem adição de probiótico) e com probiótico, onde foram incluídos $4,5 \times 10^{9}$ UFC/animal/dia de Saccaromyces cerevisiae e 3,1 x $10^{7}$ UFC/animal/dia de Lactobacillus casei. O experimento teve duração de 38 dias, dividido em dois períodos de 19 dias. No presente trabalho o fornecimento de probiótico contendo levedura ativa Saccharomyces Cerevisiae e bactéria lática Lactobacillus casei não apresentou influência no consumo e na digestibilidade da MS, MO, PB, FDN e FDA, pH ruminal, $\mathrm{N}_{-} \mathrm{NH}_{3}$ ruminal, e NUP, indicando que pode ser usado na alimentação de bovinos quando for necessário.

Palavras-chave: Consumo, digestibilidade, levedura, nitrogênio amoniacal, nitrogênio uréico plasmático, $\mathrm{pH}$

\section{Abstract}

The objective of this work was to evaluate the effects of Saccharomices cerevisiae and Lactobacillus casei in bovine diets, on dry matter (DM), organic matter (OM), crude protein $(\mathrm{CP})$, neutral detergent fiber (NDF) and acid detergent fiber (ADF) intake and digestibility, ruminal $\mathrm{pH}$ and ammonia nitrogen $(\mathrm{N}-\mathrm{NH} 3)$ and plasma urea nitrogen $(\mathrm{PUN})$. Rations were isoproteic $(13,04 \% \mathrm{CP})$ and isoenergetic $(66,39 \% \mathrm{TDN})$ with sorghum silage used as roughage $(50 \%$ of DM). Six ruminal-cannulated males,

\footnotetext{
${ }^{1}$ Dissertação de mestrado do primeiro autor, do Dept ${ }^{\circ}$ de Zootecnia, Pós-Graduação em Produção Animal, CCA, Universidade Estadual de Londrina de Londrina, UEL, PR.

${ }^{2}$ Discente de Doutorado em Ciência Animal, UEL, Londrina, PR. E-mail: nandomassar@hotmail.com

${ }^{3}$ Profs. Drs. do Dept ${ }^{\circ}$ de Zootecnia, UEL, Londrina, PR. E-mail: leandro@uel.br; anapaula_fortaleza@uel.br; elar@uel.br; maafbarbosa@uel.br; jrbumbieri@uel.br;mizubuti@uel.br; odimari@uel.br

${ }^{4}$ Discente de Doutorado, de Pós-graduação em Ciência Animal, área de Produção Animal, UEL, Londrina, PR. E-mail: brussiberan@yahoo.com.br

${ }^{5}$ Pesquisador, Montanapec, Londrina, PR. E-mail: val_montana@yahoo.com.br

* Autor para correspondência
} 
castrated, $1 / 2 \operatorname{Gir}^{1} / 2$ Holstein crossbred, with average live wight of $317 \mathrm{~kg}$ and 24 months old were utilized. Treatments were determined as control (without probiotic addition) and with probiotic, which contained 4,5 x $109 \mathrm{CFU} /$ animal/day of Saccaromyces cerevisiae and 3,1 x $107 \mathrm{CFU} /$ animal/day of Lactobacillus casei. The experiment lasted 38 days, divided in two periods of 19 days. In the present work, the supply of live yeast Saccharomyces Cerevisiae and lactic bacteria Lactobacillus casei had no influence on DM, $\mathrm{OM}, \mathrm{CP}, \mathrm{NDF}$ and $\mathrm{ADF}$ intake and digestibility, ruminal $\mathrm{pH}$, ruminal N-NH3 and PUN, indicating that can be used in cattle feed when necessary.

Key words: Ammonia nitrogen, consumption, digestibility, $\mathrm{pH}$ plasma urea nitrogen, yeast

\section{Introdução}

O território brasileiro tem uma vasta área de terras cultiváveis, grande parte desta, está situada entre os trópicos, apresentando grande potencial produtivo principalmente, no período da primavera e verão. A sazonalidade na produção de forragem aliadas a baixa qualidade e a baixa eficiência de utilização das fibras fez com que os produtores buscassem alternativas para melhorar a produtividade pecuária. Altos níveis de produtividade não podem ser suportados apenas por forragens e frequentemente grãos e seus co-produtos são utilizados para aumentar o valor nutricional das dietas para ruminantes.

As inclusões de grãos na ração altera os padrões de fermentação no rúmen, aumentando a produção de lactato, causando redução do pH ruminal, redução na motilidade, rumenitis e paraqueratose (GOES, et al., 2005).

A manipulação da fermentação ruminal pode ser feita pela adição de substâncias, como enzimas, ionóforos, antibióticos e os aditivos alimentares microbianos (GOES et al., 2005). Este aditivos atuam basicamente na competição ou na inibição de microorganismos indesejáveis. Além disso, podem favorecer o desenvolvimento de microorganismos fermentadores de fibra, melhorando os padrões de fermentação e o sistema imunológico.

O risco da presença de resíduos de antibióticos no leite e na carne e seus efeitos na saúde humana, fez com que a União Européia proibisse em 2006 a utilização de antibiótico como promotor de crescimento. Como alternativa tem-se o uso de probiótico que possuem características que atendem às exigências internacionais dos importadores de carne brasileira (GATTASS et al., 2008a). Segundo Martin e Nisbet (1992) as culturas de leveduras podem atuar fornecendo ácidos dicarboxilicos estimuladores de bactérias que utilizam acido lático, evitando fortes flutuações no $\mathrm{pH}$ ruminal, além de liberarem fatores de crescimento como: enzimas, vitaminas do complexo B e aminoácidos. Newbold et al. (1995) constataram que as leveduras removem o oxigênio que chega ao rúmen, favorecendo o desenvolvimento das bactérias celulolíticas, melhorando a digestibilidade da fibra.

O aumento na atividade microbiana eleva a utilização da amônia, a síntese e o fluxo de proteína microbiana para o duodeno, contribuindo para melhorar o consumo de MS, a eficiência do metabolismo energético e o desempenho animal (NEWBOLD; WALLACE; McINTOSH, 1996).

O objetivo deste trabalho foi o de avaliar a inclusão de probióticos Saccharomyices cerevisiae e Lactobacillus casei sobre o consumo e digestibilidade, e observar alterações metabólicas em bovinos.

\section{Material e Métodos}

O estudo foi realizado na Unidade de Estudos de Ruminantes (UNER) da Fazenda Escola (FAZESC) e no Laboratório de Alimentos e Nutrição Animal (LANA) do Departamento de Zootecnia da Universidade Estadual de Londrina. O experimento foi realizado no período de outubro a dezembro de 2008. Foram utilizados seis bovinos machos, mestiços $1 / 2$ Holandês $1 / 2$ Gir, everminados, 
castrados, com cânula permanente no rúmen, com pesos e idades médias de $317 \mathrm{~kg}$ e 24 meses, respectivamente.

Os animais permaneceram em baias individuais cobertas, medindo 1,10 metros de largura e 3 metros de comprimento, com bebedouro e comedouro. $\mathrm{O}$ fornecimento de água foi ad libitum, e as rações fornecidas diariamente as 8:00 e 17:00 horas de forma controlada para que houvesse sobras de $10 \%$ do fornecido.

O experimento, no campo, teve duração de 38 dias, sendo dividido em dois períodos de 19 dias, onde os 15 primeiros dias de cada período foram destinados à adaptação dos animais e os quatro últimos dias de cada período foram destinados a colheita de amostras.

Para a formulação das rações experimentais foram utilizados como volumoso a silagem de sorgo e como concentrados o milho, farelo de soja e suplemento mineral. A composição químicobromatológica dos ingredientes usados no estudo pode ser visualizada na Tabela 1.

As rações experimentais foram formuladas de forma isoprotéicas e isoenergéticas, de acordo com as exigências nutricionais propostas pelo NRC (1996) para um ganho médio diário de $1,300 \mathrm{~kg} / \mathrm{dia}$, Tabela 2.

$\mathrm{O}$ premix de micro minerais utilizado neste experimento foi o mesmo para ambos os tratamentos, o que diferiu os tratamentos foi a inclusão de 4,5 X $10^{9} \mathrm{UFC} /$ animal/dia de Saccaromyces cerevisiae e 3,1 X 107 UFC/animal/dia de Lactobacillus casei no premix incluído no tratamento probiótico, conforme recomendações do fabricante.

Para o cálculo de consumo em $\mathrm{kg} / \mathrm{dia}$, \% Peso Vivo (PV) e em $\mathrm{g} / \mathrm{kgPV}^{0,75}$, foram colhidas amostras de sobras e fornecido. Após a colheita as amostras foram pré-secas e acondicionadas para determinação de matéria seca (MS), matéria orgânica (MO), proteína bruta $(\mathrm{PB})$, fibra em detergente neutro (FDN) e da fibra em detergente ácido (FDA) segundo
Silva e Queiroz (2002). A pesagem dos animais foi realizada antes de começar o experimento e repetida no último dia de cada período após um jejum de 16 horas.

Para determinação da digestibilidade da MS, MO, PB, FDN e FDA com uso do óxido crômico $\left(\mathrm{Cr}_{2} \mathrm{O}_{3}\right)$ cada animal recebeu 10 gramas de $\mathrm{Cr}_{2} \mathrm{O}_{3}$ via fístula ruminal, do $10^{\circ}$ ao $19^{\circ}$ dia de cada período com o objetivo de saturar o rúmen, segundo metodologia descrita por Coelho da Silva e Leão (1979).

Foram retiradas amostras de 300 gramas de fezes diretamente do reto dos animais, do $16^{\circ}$ ao $19^{\circ}$ dia avançando em duas horas a cada dia, de tal forma que em quatro dias foram obtidas 12 amostras que representaram 24 horas (02:00, 04:00, 06:00, 08:00, 10:00, 12:00, 14:00, 16:00, 18:00, 20:00, 22:00 e 24:00). As amostras colhidas foram processadas, pré-secas, para posterior análise de MS, MO, PB, FDN e FDA, realizados no LANA e determinação de cromo conforme citado por Silva e Queiroz (2002), realizada no laboratório da empresa LABORSOLO ${ }^{\circledR}$. As quantificações dos indicadores internos foi obtida após 144 horas de incubação in situ de amostras dos alimentos, sobras e das fezes.

As colheitas de líquido ruminal para análise de $\mathrm{pH}$ e nitrogênio amoniacal, assim como as colheitas de sangue para análise de nitrogênio uréico plasmático foram feitas no último dia de cada período, nos tempos $0,2,4,6$ e 8 horas, considerando o tempo zero a colheita realizada antes da alimentação dos animais.

As amostras de líquido ruminal para determinação de $\mathrm{pH}$ e $\mathrm{N}-\mathrm{NH}_{3}$ foram colhidas em quatro pontos diferentes do rúmen, e depois filtradas. $\mathrm{O} \mathrm{pH}$ foi determinado imediatamente com o auxílio de um potenciômetro digital Tecnal ${ }^{\circledR}$ modelo TEC $3 \mathrm{MP}$, e $50 \mathrm{~mL}$ de cada amostra de líquido ruminal foi acidificada com $1 \mathrm{~mL}$ de ácido sulfúrico $1: 1$, acondicionadas em frascos plásticos e congeladas a $-20{ }^{\circ} \mathrm{C}$, para posteriores determinações dos teores de $\mathrm{N}-\mathrm{NH}_{3}$. 
Tabela 1.Composição química dos ingredientes utilizados nas rações (base MS).

\begin{tabular}{lccc}
\hline \multirow{2}{*}{ Nutrientes } & \multicolumn{3}{c}{ Ingredientes } \\
\cline { 2 - 4 } \multicolumn{1}{c}{ MS } & MT & FS \\
\hline Matéria seca & 33,75 & 86,99 & 89,63 \\
Matéria orgânica & 93,33 & 98,60 & 93,20 \\
Matéria mineral & 6,67 & 1,40 & 6,80 \\
Proteína bruta & 9,29 & 10,47 & 54,74 \\
Extrato etéreo & 2,25 & 4,12 & 2,82 \\
Fibra em detergente neutro & 75,61 & 7,45 & 15,10 \\
Fibra em detergente ácido & 32,55 & 2,89 & 6,49 \\
Fibra bruta & 34,43 & 6,62 & 17,80 \\
Extrato não nitrogenado & 47,36 & 77,39 & 17,84 \\
Nutrientes digestíveis totais & 56,12 & 80,44 & 69,34 \\
\hline
\end{tabular}

$\mathrm{SS}=$ Silagem de Sorgo; FS = Farelo de Soja; MT = Milho Triturado.

Nutrientes digestíveis totais - Estimado conforme (KEARL, 1982). Silagem de sorgoN: NDT\% $=-21,9391+(1,0538 \times$ PB) + $(0,9738 \times \mathrm{ENN})+(3,0016 \times \mathrm{EE})+(0,4590 \times \mathrm{FB})$, Farelo de Soja: NDT\%= 40,3217+ $(0,5398 \times \mathrm{PB})+(0,4448 \times \mathrm{ENN})+(1,4223$ x EE) - (0,7007 x FB), Milho Triturado: NDT\% $=40,2625+(0,1969 \times \mathrm{PB})+(0,4028 \times \mathrm{ENN})+(1,903 \times \mathrm{EE})-(0,1379 \times \mathrm{FB})$.

Fonte: Elaboração dos autores.

Tabela 2. Composição percentual e química das rações (base MS).

\begin{tabular}{lc}
\hline Alimentos & $\%$ \\
\hline Silagem de sorgo & 50,00 \\
Farelo de soja & 5,60 \\
Milho triturado & 42,85 \\
Uréia & 0,30 \\
Calcário calcítico & 0,17 \\
Fosfato bicálcico & 0,48 \\
Cloreto de sódio & 0,49 \\
Premix microminerais* & 0,11 \\
\hline \multicolumn{1}{c}{ Composição química } \\
\hline \multicolumn{2}{c}{} \\
\hline Nutrientes & $\% 00,00$ \\
\hline Proteína bruta & 13,04 \\
Proteína degradável no rúmen & 8,86 \\
Extrato etéreo & 3,05 \\
Fibra em detergente neutro & 54,70 \\
Nutrientes digestíveis totais & 66,39 \\
\hline
\end{tabular}

* Níveis de Garantia/kg = 130 mg Cobalto; 6000 mg Cobre; 220 g Enxofre, 5000 mg Ferro; 320 mg Iodo; 18000 mg Manganês; 150 mg Selênio; 25000 mg Zinco; 2.000.000 UI Vit. A; 500.000 UI Vit. D; 12500 UI Vit. E; 5000 mg Antioxidante.

Fonte: Elaboração dos autores.

$\mathrm{O} \mathrm{N}-\mathrm{NH}_{3}$ foi determinado pela destilação de 2 $\mathrm{mL}$ de cada amostra com adição de $5 \mathrm{~mL}$ de $\mathrm{KOH} 2 \mathrm{~N}$ em aparelho tipo Kjedhal. O destilado foi recebido em $10 \mathrm{~mL}$ de $\mathrm{H}_{3} \mathrm{BO}_{3} 2 \%$ até um volume final de
$50 \mathrm{~mL}$, seguindo para titulação com $\mathrm{HCl} 0,005 \mathrm{~N}$, segundo a técnica de Fenner (1965) adaptada por Vieira (1980).

As amostras de sangue foram colhidas por punção na veia jugular em tubos 13 X $17 \mathrm{~mm}$ com heparina, em seguida o conteúdo foi homogeneizado suavemente e centrifugado à $4000 \mathrm{RPM}$ por 10 minutos para a obtenção do plasma, utilizado para a determinação do Nitrogênio Uréico Plasmático (NUP), pelo método enzimático colorimétrico com o kit Labtest ${ }^{\circledR}$.

O experimento foi conduzido em dois períodos, onde no primeiro período, foram sorteados aleatoriamente dois grupos de três animais, sendo que um dos grupos recebeu o tratamento contendo o probiótico e o outro grupo recebeu o tratamento sem o probiótico. No segundo período foram invertidos os animais para os tratamentos, seguindo um delineamento estatístico tipo cross-over. Para os parâmetros de consumo de componentes químicos avaliados foi utilizado modelo matemático:

$$
\text { Yijk }=\mu+\mathrm{Ai}+\mathrm{Pj}+\mathrm{Tk}+\text { Eijk }
$$

Onde: $\mathrm{A}=$ Animal, $\mathrm{P}=$ Período, $\mathrm{T}=$ Tratamento e $\mathrm{E}=$ Erro experimental. 
Para as parcelas subdivididas $(\mathrm{pH}, \mathrm{N}-\mathrm{NH} 3 \mathrm{e}$ NUP) o modelo matemático utilizado foi:

Yijkl $=\mu+\mathrm{Ai}+\mathrm{Pj}+\mathrm{Tk}+(\mathrm{Ai} \times \mathrm{Pj} \mathrm{x} \mathrm{Tk})+\mathrm{Hl}+$ $(\mathrm{Tk} \times \mathrm{Hl})+$ Eijkl

Onde: $\mathrm{A}=$ Animal, $\mathrm{P}=$ Período, $\mathrm{T}=$ Tratamento $\mathrm{H}=$ Tempo, Ai x Pj x Tk = Erro experimental parcela, Tk x Hl = Interação Tratamento x Tempo e $\mathrm{E}=$ Erro experimental - sub-parcela.

Para análise de variância foi utilizado o procedimento GLM, do programa estatístico SAS (2001).

As diferenças entre as médias para as diversas variáveis avaliadas foram verificadas por meio do Teste Tukey, considerando-se 5\% como nível de significância.

\section{Resultados e Discussão}

Não foram encontradas diferenças $(\mathrm{P}>0,05)$ para $\mathrm{o}$ consumo dos nutrientes avaliados, em kg/dia, \%Peso Vivo e em $\mathrm{g} / \mathrm{kg} \mathrm{PV}^{0,75}$, como pode ser observado na Tabela 3. Estes resultados foram semelhantes aos encontrados por Zeoula et al.(2008) e por Gattass et al. (2008b) ao medir o consumo de nutrientes em bovinos, alimentados com rações contendo $50 \%$ de concentrado possuindo ou não levedura.

Queiroz et al. (2004) não observaram diferenças no consumo de MS em \% do PV e g/kg PV ${ }^{0,75}$, para bovinos, com adição de cinco ou dez gramas de enzimas mais cinco gramas de leveduras, em rações contendo 35\% de concentrado. Santos et al. (2006) fornecendo dietas com diferentes teores de amido, (22 e $32 \%$ ), com e sem adição de levedura a vacas secas não encontraram diferenças no CMS em $\mathrm{Kg}$ /dia.

Williams et al. (1991), ao avaliar a inclusão de probióticos em rações para vacas leiteiras contendo 40 ou 50\% de concentrado, observaram maior consumo de matéria seca quando os animais consumiram maior porcentagem de concentrado. Nicodemo (2001) afirma que a levedura teria maior efeito em dietas com maiores percentagens de concentrado.
Newbold et al. (1995) relataram que nem todas as culturas de Saccharomyces cerevisiae modificam efetivamente a população bacteriana ruminal. Segundo Wallace (1994), os efeitos da utilização de leveduras são altamente dependentes da dose e da dieta fornecida.

Os coeficientes de digestibilidade dos nutrientes avaliados, assim como o uso de diferentes indicadores para determinação da digestibilidade, não apresentaram diferenças $(\mathrm{P}>0,05)$ em função da adição do probiótico, como pode ser observado na Tabela 4.

Os resultados obtidos para esses parâmetros são semelhantes aos obtidos por Doreau e Jouany (1998) ao avaliarem os efeitos da inclusão de culturas de Saccharomyces cerevisiae, em vacas em lactação consumindo ração com $40 \%$ de concentrado.

Tabela 3. Consumo médio de matéria seca (CMS), matéria orgânica $(\mathrm{CMO})$, proteína bruta $(\mathrm{CPB})$, fibra em detergente neutro (CFDN) e da fibra em detergente ácido (CFDA) dos animais por tratamento.

\begin{tabular}{|c|c|c|c|}
\hline \multirow{2}{*}{ Nutrientes } & \multicolumn{2}{|c|}{ Tratamentos } & \multirow{2}{*}{ CV (\%) } \\
\hline & Controle & Probiótico & \\
\hline \multicolumn{4}{|c|}{$\mathrm{kg} / \mathrm{dia}$} \\
\hline CMS & 9,00 & 8,99 & 11,19 \\
\hline $\mathrm{CMO}$ & 8,43 & 8,46 & 11,13 \\
\hline CPB & 1,06 & 1,06 & 12,65 \\
\hline CFDN & 5,62 & 5,18 & 16,06 \\
\hline CFDA & 2,34 & 2,52 & 14,44 \\
\hline \multicolumn{4}{|c|}{$\% \mathrm{PV}$} \\
\hline CMS & 2,41 & 2,52 & 13,66 \\
\hline $\mathrm{CMO}$ & 2,26 & 2,37 & 13,94 \\
\hline CPB & 0,28 & 0,30 & 15,22 \\
\hline CFDN & 1,50 & 1,45 & 27,79 \\
\hline CFDA & 0,63 & 0,71 & 17,88 \\
\hline \multicolumn{4}{|c|}{$\mathrm{g} / \mathrm{kg}$ PV0,75 } \\
\hline CMS & 105,76 & 109,34 & 12,93 \\
\hline CMO & 99,22 & 102,98 & 13,10 \\
\hline CPB & 12,42 & 12,90 & 14,27 \\
\hline CFDN & 65,74 & 62,80 & 27,90 \\
\hline CFDA & 27,64 & 30,72 & 16,60 \\
\hline
\end{tabular}

$\mathrm{CV}=$ coeficiente de variação; $\mathrm{PV}=$ Peso Vivo; $\mathrm{g} / \mathrm{kg} \mathrm{PV}^{0,75}=$ peso metabólico; $(\mathrm{P}>0.05)$.

Fonte: Elaboração dos autores. 
No trabalho realizado por Gattass et al. (2008b) não foram encontradas diferenças na digestibilidade dos nutrientes da dieta quando incluíram probiótico. O mesmo foi observado por Queiroz et al. (2004) trabalhando com bezerros mestiços consumindo ração com $35 \%$ de concentrado.

Zeoula et al. (2008) fornecendo ração com 50\% de concentrado observaram valores superiores do coeficiente de digestibilidade aparente total (CDT) da FDN, FDA e do amido e valores inferiores para o CDT da PB em rações contendo leveduras, quando comparados aos valores obtidos com a ração testemunha. Já os CDT da MS e MO não foram influenciados pela adição de levedura. Os autores atribuíram o aumento na digestibilidade de FDN e FDA a uma melhor atividade das bactérias celulolíticas.

Piva et al. (1993) relataram aumento na digestibilidade de nutrientes, principalmente das fibras. Wallace (1994) cita aumentos na digestão da fibra pelo incremento na viabilidade microbiana ruminal através da remoção do oxigênio por Saccharomyces cerevisiae.

Os valores referentes ao $\mathrm{pH}$ do líquido ruminal, em função dos tempos de colheita e dos tratamentos estão expostos na Tabela 5 . Não foram verificadas diferenças significativas $(\mathrm{P}>0,05)$ para os valores de $\mathrm{pH}$ do líquido ruminal dos animais recebendo rações contendo ou não probióticos. Resultado semelhante foram observados por Gattass et al. (2008a) alimentando bovinos com rações contendo $50 \%$ de concentrado.

Segundo Orskov (1988) valores de $\mathrm{pH}$ inferiores a 6,2 acarretam em redução na digestão da fibra, já que as bactérias celulolíticas são sensíveis a pH inferior a este valor.

Os valores de $\mathrm{pH}$ em relação aos diferentes tempos e tratamentos variaram entre 6,17 e 6,75 , sendo os valores médios observados de 6,36 e 6,43 para os tratamentos controle e probiótico, respectivamente. $\mathrm{O}$ pH não interferiu na digestão das fibras pelos microorganismos ruminais.
Tabela 4. Coeficientes de digestibilidade da matéria seca (CDMS), matéria orgânica (CDMO), proteína bruta (CDPB), fibra em detergente neutro (CDFDN) e da fibra em detergente ácido (CDFDA), obtidos com o uso da matéria seca indigestível (MSi), da fibra em detergente neutro indigestível (FDNi) e por óxido crômico $\left(\mathrm{Cr}_{2} \mathrm{O}_{3}\right)$ Indicadores.

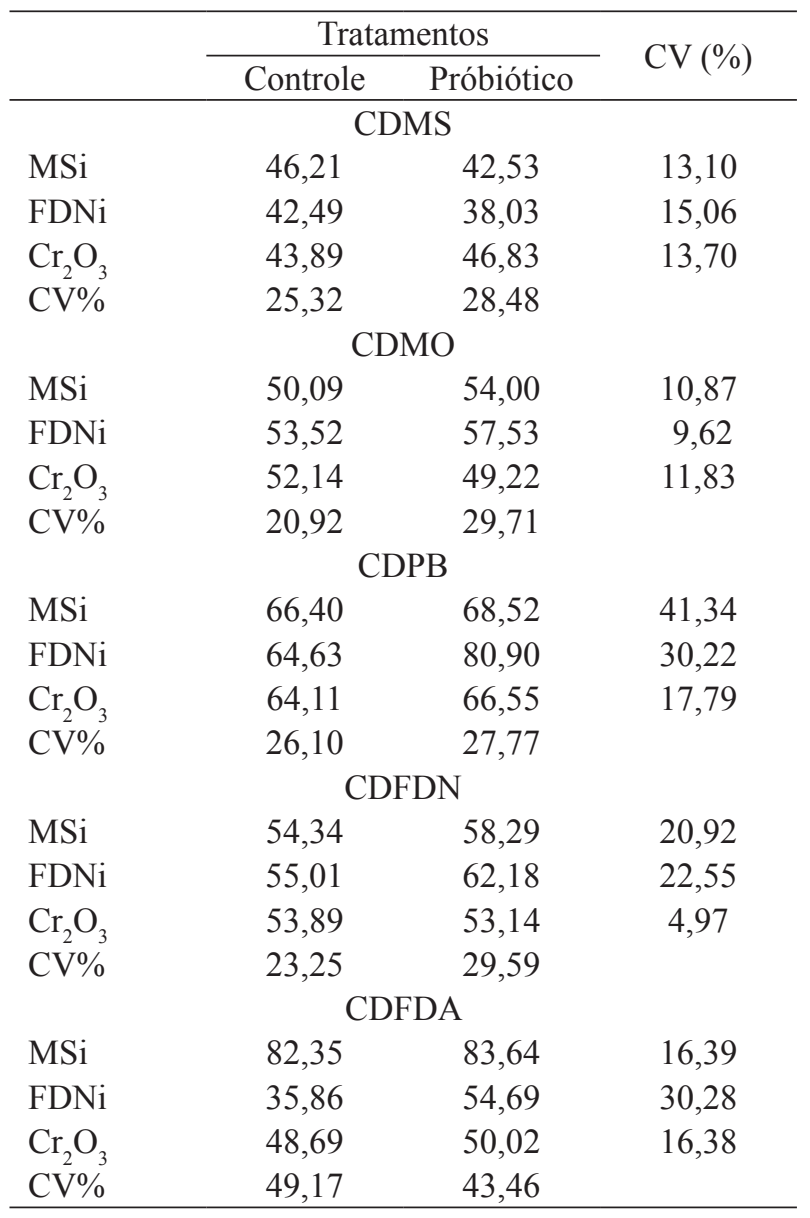

$\mathrm{CV}=$ coeficiente de variação; $(\mathrm{P}>0,05)$.

Fonte: Elaboração dos autores.

Segundo Pereira et al. (2001) a redução no valor do $\mathrm{pH}$ observado nas primeiras horas após o fornecimento da ração é dada pelo aumento na concentração de ácidos orgânicos provenientes da fermentação ruminal.

Fereli et al. (2010) avaliando rações contendo $70 \%$ de concentrado observou os menores valores de pH quatro horas após o fornecimento do alimento. Este comportamento da curva de $\mathrm{pH}$ é semelhante ao observado no presente trabalho e provavelmente 
ocorra devido a intensa fermentação de carboidratos após a alimentação e a elevação na produção de ácidos graxos voláteis no rúmen.

Gattass et al. (2008a) encontraram valores mínimos de $\mathrm{pH}$ duas horas após a refeição $(6,60$ e 6,56) e máximos de 6,86 e 6,99 antes da alimentação nos grupos com e sem adição de cultura de levedura, respectivamente. Estes valores são superiores aos encontrados neste trabalho e podem ser explicados pela composição do concentrado da ração. Gattass et al. (2008a) utilizaram na formula da ração concentrada $52 \%$ de casquinha de soja, que possui fermentação lenta quando comparada ao milho e farelo de soja utilizados no presente trabalho.

Tabela 5. Valores médios de $\mathrm{pH}$ do líquido ruminal dos animais antes ( 0 horas) e após o fornecimento da refeição (2, 4,6 e 8 horas).

\begin{tabular}{lccc}
\hline \multirow{2}{*}{$\begin{array}{c}\text { Tempo } \\
\text { (horas) }\end{array}$} & \multicolumn{2}{c}{ Tratamentos } & \multirow{2}{*}{ CV\% } \\
\cline { 2 - 3 } & Controle & Probiótico & \\
\hline 0 & 6,70 & 6,75 & 7,94 \\
2 & 6,38 & 6,42 & 6,00 \\
4 & 6,17 & 6,32 & 4,28 \\
6 & 6,20 & 6,33 & 5,91 \\
8 & 6,34 & 6,33 & 5,08 \\
\hline Média & 6,36 & 6,43 & \\
\hline
\end{tabular}

$\mathrm{CV}=$ coeficiente de variação; $(\mathrm{P}>0,05)$.

Fonte: Elaboração dos autores.

Segundo Williams et al. (1991), a elevação do pH ruminal 4 horas após o fornecimento de ração com 50\% de concentrado, e suplementação com cultura de levedura, provavelmente é conseqüência da modulação dos picos de lactato e da redução na concentração de ácido lático no líquido ruminal.

Os valores referentes ao nitrogênio amoniacal, em função dos diferentes tempos de coleta e tratamentos não apresentaram diferenças significativas como pode ser observado na Tabela 6 .

Pereira et al. (2001) não encontraram influencias do fornecimento de leveduras na concentração média de $\mathrm{N}-\mathrm{NH}_{3}$ ruminal. Miranda et al. (1996), em experimento com novilhas alimentadas com rações contendo 40 ou $60 \%$ de concentrado, com e sem adição de levedura, observaram que a concentração de $\mathrm{N}_{-} \mathrm{NH}_{3}$ três horas após a alimentação foi maior no grupo que recebeu $10 \mathrm{~g}$ de cultura de levedura/ animal/dia.

Gattass et al. (2008a) suplementando os animais com $1 \mathrm{~g}$ de levedura/100kg de PV encontrou maiores concentrações de $\mathrm{N}_{-} \mathrm{NH}_{3}$ quatro horas após o fornecimento da refeição, 14,15 e 13,95 $\mathrm{mg} / \mathrm{dL}$ para o tratamento com levedura e controle, respectivamente. Diferindo do observado no presente trabalho, que obteve maiores concentrações de $\mathrm{N}_{-} \mathrm{NH}_{3}$ duas horas após o fornecimento da ração 15,99 e $14,17 \mathrm{mg} / \mathrm{dL}$ para os tratamentos controle e probiótico, respectivamente; isso se deve provavelmente à diferença na fermentação das matérias primas usadas na ração concentrada.

Os valores médios obtidos neste estudo para a concentração de $\mathrm{N}_{-} \mathrm{NH}_{3}$ foram, respectivamente, 7,7 e $8,53 \mathrm{mg} / \mathrm{dL}$ para os grupos com ou sem adição de probióticos, o que permite inferir que a síntese de proteína microbiana no rúmen não esteve limitada, uma vez que a dieta continha $13,4 \%$ de $\mathrm{PB}$ na MS e que as concentrações ruminais médias de $\mathrm{N}-\mathrm{NH}_{3}$ foram superiores a $6,2 \mathrm{mg} / \mathrm{dL}$, nível considerado por Hoover (1986) como ótimo para o crescimento e a degradação microbiana em bovinos alimentados com dietas com mais de 6\% de PB.

Tabela 6. Valores médios de $\mathrm{N}_{-} \mathrm{NH}_{3}(\mathrm{mg} / \mathrm{dL})$ no líquido ruminal dos animais antes ( 0 horas) e após o fornecimento da refeição $(2,4,6$ e 8 horas $)$.

\begin{tabular}{lrcc}
\hline \multirow{2}{*}{$\begin{array}{r}\text { Tempo } \\
\text { (horas) }\end{array}$} & \multicolumn{2}{c}{ Tratamentos } & \multirow{2}{*}{ CV\% } \\
\cline { 2 - 3 } & Controle & Probiótico & \\
\hline 0 & 8,72 & 7,88 & 19,31 \\
2 & 15,99 & 14,17 & 32,39 \\
4 & 7,26 & 6,97 & 23,25 \\
6 & 4,87 & 4,61 & 10,87 \\
8 & 5,81 & 4,87 & 21,58 \\
\hline Média & 8,53 & 7,7 & \\
\hline
\end{tabular}

$\mathrm{CV}=$ coeficiente de variação; $(\mathrm{P}>0,05)$.

Fonte: Elaboração dos autores. 
A otimização do crescimento microbiano e da digestão da matéria orgânica no rúmen ocorre de forma adequada, com concentrações de N-NH3 entre 3,3 a $8,0 \mathrm{mg} / \mathrm{dL}$, respectivamente, porém variações nestas concentrações podem ocorrem em decorrência a máximas taxas de crescimento microbiano que ocasionam mudanças no ambiente ruminal, na microbiota envolvida na utilização e produção de compostos amoniacais (HOOVER, 1986).

A quantidade de $\mathrm{N}-\mathrm{NH}_{3}$ no líquido ruminal está diretamente relacionada com o perfil de degradação da proteína dietética e a disponibilidade de energia para o crescimento microbiano (COELHO DA SILVA; LEÃO 1979).

Não foram encontradas diferenças significativas para as concentrações plasmáticas de NUP, entre os tratamentos avaliados (Tabela 7). Resultado semelhante foi encontrado por Santos et al. (2006) que trabalhou com vacas em lactação consumindo ração com $50 \%$ de concentrado com e sem a adição de leveduras.

Tabela 7. Valores médios de NUP (mg/dL) no líquido ruminal dos animais antes ( 0 horas) e após o fornecimento das refeições (2, 4, 6 e 8 horas).

\begin{tabular}{lccc}
\hline \multirow{2}{*}{$\begin{array}{l}\text { Tempo } \\
\text { (horas) }\end{array}$} & \multicolumn{2}{c}{ Tratamentos } & \multirow{2}{*}{ CV\% } \\
\cline { 2 - 3 } 0 & Controle & Probiótico & \\
\hline 0 & 9,11 & 5,56 & 11,42 \\
4 & 12,72 & 11,90 & 17,91 \\
6 & 9,75 & 8,29 & 23,55 \\
8 & 7,67 & 7,74 & 22,39 \\
\hline Média & 7,93 & 7,65 & 33,25 \\
\hline
\end{tabular}

$\mathrm{CV}=$ coeficiente de variação; $(\mathrm{P}>0,05)$.

Fonte: Elaboração dos autores.

Broderick e Clayton (1997) consideram valores de NUP entre 7 e $19 \mathrm{mg} / \mathrm{dL}$ adequados para vacas em lactação. Os valores médios encontrados neste trabalho para o tratamento controle epara otratamento probiótico, 9,44 e 8,23 mg/dL, respectivamente, estão entre os intervalos considerados adequados.
Isto pode reforçar a hipótese que os animais utilizados neste experimento estavam sendo capazes de utilizar boa parte da proteína consumida.

As concentrações de NUP estão intimamente ligadas com a concentração de $\mathrm{N}_{-} \mathrm{NH}_{3}$ no rúmen (RENNÓ et al., 2000). Essa relação pode ser observada neste estudo onde os menores valores médios de $\mathrm{N}-\mathrm{NH}_{3} 7,7 \mathrm{mg} / \mathrm{dL}$, e NUP $8,83 \mathrm{mg} / \mathrm{dL}$ foram encontrados no tratamento com probiótico.

Quando a produção de amônia no rúmen é excedente ao requerido, o excesso vai ser absorvido pelo epitélio da parede ruminal e é transportado para o fígado, entrando no ciclo da uréia (VAN SOEST, 1994), aumentando as concentrações de NUP, podendo ocasionar perdas por excreção urinaria (OLIVEIRA et al., 2008) e afetar negativamente o sistema reprodutivo (BUTLER; CALAMAN; BEAM, 1996).

\section{Conclusões}

O fornecimento de probiótico contendo levedura ativa Saccharomyces Cerevisiae e bactéria lática Lactobacillus casei não influenciou o consumo e a digestibilidade dos nutrientes, assim como os parâmetros depHruminal, $\mathrm{N}-\mathrm{NH}_{3}$, eNUPembovinos consumindo ração com $50 \%$ de concentrado. Sendo assim, pode ser usado na alimentação de animais ruminantes, quando o mesmo for economicamente viável.

\section{Referências}

BRODERICK, G. A.; CLAYTON, M. K. A statistical evaluation of animal and nutritional factors influencing concentrations of milk urea nitrogen. Journal of Dairy Science, Madison, v. 80, n. 11, p. 2964-2971, 1997

BUTLER, W. R.; CALAMAN, J. J.; BEAM, S. W. Plasma and milk urea nitrogen in relation to pregnancy rate in lactating dairy cattle. Journal of Animal Science, Madison, v. 74, n. 4, p. 858-865, 1996.

COELHO DA SILVA, J. F.; LEÃO, M. I. Fundamentos de nutrição de ruminantes. Piracicaba: Livroceres, 1979. $380 \mathrm{p}$ 
DOREAU, M.; JOUANY, J. P. Effect of a Saccharomyces cerevisiae Culture on Nutrient Digestion in Lactating Dairy Cows. Journal of Dairy Science, Madison, v. 81, n. 12, p. 3214-3221, 1998.

FERELI, F.; BRANCO,A. F.; JOBIM, C.C.; CONEGLIAN, S. M.; GRANZOTTO, F.; BARRETO, J. C. Monensina sódica e Saccharomyces cerevisiae em dietas para bovinos: fermentação ruminal, digestibilidade dos nutrientes e eficiência de síntese microbiana. Revista Brasileira de Zootecnia, Viçosa, MG, v. 39, n. 1, p. 183-190, 2010.

GATTASS, C. B. A.; MORAIS, M. G.; ABREU, U. G. P.; FRANCO, G. L.; STEIN, J.; LEMPP, B. Efeito da suplementação com cultura de levedura na fermentação ruminal de bovinos de corte. Revista Brasileira de Zootecnia, Viçosa, MG, v. 37, n. 4, p. 711-716, 2008.

GATTASS, C. B. A.; MORAIS, M. G.; ABREU, U. G. P.; LEMPP, B.; STEIN, J.; ALBERTINI, T. Z.; FRANCO, G. L. Consumo, digestibilidade aparente e ganho de peso em bovinos de corte confinados e suplementados com cultura de levedura (Saccharomyces cerevisiae cepa 1026). Ciência Animal Brasileira, Goiânia, v. 9, n. 3, p. 535-542, 2008b.

GOES, R. H. T. B.; ALVES, D. D.; VALADARES FILHO, S. C.; MARSON, S. C. Utilização de aditivos alimentares microbianos na alimentação de bovinos de corte e leite: Revisão. Arquivo de Ciência Veterinária e Zoologia, UNIPAR, v. 8, n. 1, p. 47-56, 2005.

HOOVER, W. H. Chemical factores involved in ruminal fiber digestion. Journal of Dairy Science, Madison, v. 69, n. 10, p. 2755-2766, 1986.

MARTIN, S. A.; NISBET, D. J. Symposium: direct-fed microbials and rumen fermentation. Journal of Dairy Science, Madison, v. 75, n. 6, p. 1736-1744, 1992.

MIRANDA, R. L.A.; MENDOZA, M.G.D.; BÁRCENAGAMA, J. R.; GONZÁLES, M. S. S.; FERRARA, R.; ORTEGA, C. M. E.; COBOS, P. M. A. Effect of Saccharomyces cerevisae or Aspergillus oryzae cultures and NDF level on parameters of ruminal fermentation. Animal Feed Science Technology, Amsterdam, v. 63, n. 1-4, p. 289-296, 1996.

NATIONAL RESEARCH COUNCIL - NRC. Nutrients requirements of beef cattle. 7. ed. Washington: National Academic Press, 1996.

NEWBOLD, C. J.; WALLACE, R. J.; CHEN, X. B.; McINTOSH, F. M. Different strains of Saccharomyces cerevisae differ in their effects on ruminal bacterial numbers in vitro and in sheep. Journal of Animal Science, Madison, v. 73, n. 6, p. 1811-1818, 1995.

NEWBOLD, C. J.; WALLACE, R. J.; McINTOSH, F. M. Mode of action of the yeast Saccharomyces cerevisiae as a feed addtive for ruminants. British Journal of Nutrition, Londres, v. 76, n. 2, p. 249-261, 1996.

NICODEMO, M. L. F. Uso de aditivos na dieta de bovinos de corte. Campo Grande: EMBRAPA Gado de corte, 2001. $54 \mathrm{p}$.

OLIVEIRA, R. L.; PEREIRA, J. C.; NACIMENTO JÚNIOR, D.; VIERIRA, R. A. M.; FERREIRA, G. D. G.; BAGALDO, A. R.; RIBEIRO, M. D. Consumo, digestibilidade e N-Uréico plasmático em novilhas que receberam suplementos com diferentes níveis de proteína não-degradável no rúmen. Ciência Animal Brasileira, Goiânia, v. 9, n. 3, p. 563-577, 2008.

ORSKOV, E. R. Nutrición protéica de los ruminantes. Zaragoga: Acribia, 1988. 157 p.

PEREIRA, E. S.; QUEIROZ, A. C.; PAULINO, M. F.; CECON, P. R.; VALADARES FILHO, S. C.; MIRANDA, L. F.; ARRUDA, A. M. V.; FERNANDES, A. M.; CABRAL, L. S. Fontes nitrogenadas e uso de Saccharomyces cerevisiae em dietas à base cana-deaçúcar para novilhos: consumo, digestibilidade, balanço nitrogenado e parâmetros ruminais. Revista Brasileira de Zootecnia, Viçosa, MG, v. 30, n. 2, p. 563-572, 2001.

PIVA, G.; BELLADONA, S.; FUSCONI, G.; SICBALDI, F. Effects of yeast on dairy cow performance, ruminal fermentation, blood components, and milk manufacturing properties. Journal of Dairy Science, Madison, v. 76, n. 10, p. 2717-2722, 1993.

QUEIROZ, R. C.; BERGAMASHINE, A. F.; BASTOS, J. F. P.; SANTOS, P. C.; LEMOS, G. C. Uso de produto à base de enzima e levedura na dieta de bovinos: digestibilidade dos nutrientes e desempenho em confinamento. Revista Brasileira de Zootecnia, Viçosa, MG, v. 33, n. 6, p. 1548-1556, 2004.

RENNÓ, N. L.; VALADARES, R. F. D.; VALADARES FILHO, S. C.; LEÃO, M. I.; SILVA, J. F. C.; CECON, P. R.; GONÇALVES, L. C.; DIAS, H. L. C.; LINHARES, R. S. Concentração plasmática de uréia e excreção de uréia e creatinina em novilhos. Revista Brasileira de Zootecnia, Viçosa, MG, v. 29, n. 4, p. 1235-1243, 2000.

SANTOS, F. A. P.; CARMO, C. A.; MARTINEZ, J. C.; PIRES, A. V.; BITTAR, C. M. M. Desempenho de vacas em lactação recebendo dietas com diferentes teores de amido total, acrescidas ou não de levedura (Saccharomyces cerevisiae). Revista Brasileira de Zootecnia, Viçosa, MG, v. 35, n. 4, p. 1568-1575, 2006.

SILVA, D. J.; QUEIROZ, A. C. Análises de alimentos: métodos químicos e biológicos. 3. ed. Viçosa: UFV, 2002.

STATISTICAL ANALYSIS SYSTEM - SAS. User's guide: statistical analysis system institute. 6. ed. USA: NC, 1999-2001. 
VAN SOEST, P. J. Nutritional ecology of the ruminant. 2. ed. Ithaca: Comstock, 1994. 476 p.

VIEIRA, P. F. Efeito do formaldeído na proteção de proteinas e lipídios em rações para ruminantes. 1980. Tese (Doutorado em Zootecnia) - Universidade Federal de Viçosa, Viçosa.

WALLACE, R. J. Ruminal microbiology, biotechnology, and ruminant nutrition: progress and problems. Journal of Animal Science, Madison, v. 72, n. 11, p. 2992-3003, 1994.
WILLIAMS, P. E.; TAIT, C. A.; INNES, G. M.; NEWBOLD, C. J. Effects of the inclusion of yeast culture (Saccharomyces cerevisiae plus growth medium) in the diet of dairy cows on milk yield and forage degradation and fermentation patterns in the rumen of steers. Journal of Animal Science, Madison, v. 69, n. 7, p. 3016-3026, 1991.

ZEOULA, L. M.; BELESE, J. R. F.; GERON, L. J. V.; MAEDA, E. M.; PRADO, I. N.; PAULA, M. C. Digestibilidade parcial e total de rações com a inclusão de ionóforo ou probiótico para bubalinos e bovinos. Revista Brasileira de Zootecnia, Viçosa, MG, v. 37, n. 3, p. 563-571, 2008. 